\title{
Penurunan Susut Jaringan Dengan Penertiban Pemakaian Tenaga Listrik
}

\author{
Novi Gusti Pahiyanti'; Sigit Sukmajati²; Muhammad Rizal Nur ${ }^{3}$ \\ 1, 2, 3 Sekolah Tinggi Teknik PLN \\ ${ }^{1}$ novi.gusti@sttpln.ac.id
}

\begin{abstract}
The decrease in the shrinkage of the distribution network can be done through controlling the use of electricity. Before the use of electricity by consumers, electricity in the distribution network is then fed to the APP (meter and gauge) of the customer's meter and can then be used by customers for daily use. Operational control of electric power expansion that is in the PLN is an activity carried out by the PLN so that there is no loss or can minimize the losses experienced. The truth of measuring meter energy in APP has several obstacles, such as the wrong reading of kwh meters, theft of electricity, use of electricity without measuring the meter, wiring and others. Basically the shrinkage itself is divided into the first two technical losses and non-technical losses in PT PLN (Persero) Teluk Naga Area, in non-technical shrinkage is a problem that is very vigilant because of this shrinkage PLN gets a lot of losses from customers such as affecting power limit, affecting energy measurements can reach $8257.9 \mathrm{kWh} /$ month from 16 customers and experiencing losses of $13809.8 \mathrm{kWh} /$ month therefore customers who make these deviations will be subject to sanctions in the form of a fine of Rp.332,830,661 for all customers who do deviation.
\end{abstract}

Keywords: Control, Shrinkage, APP, Loss

\begin{abstract}
ABSTRAK
Penurunan susut jaringan distribusi dapat dilakukan dengan melalui penertiban pemakaian tenaga listrik. Sebelum penggunaan listrik oleh konsumen, listrik yang di jaringan distribusi kemudian dialiri ke APP (Alat Pembatas dan Pengukur) meter pelanggan lalu dapat di digunakan oleh pelanggan untuk penggunaan sehari-hari. Operasional penertiban pemekaian tenaga listrik yang ada pada PLN ialah kegiatan yang dilakukan oleh pihak PLN agar tidak adanya kerugian atau dapat meminimalisir kerugian yang dialami. Kebenaran pengukuran energi meter pada APP mempunyai beberapa kendala, seperti pada salahnya pembacaan kwh meter, pencurian listrik, pemakian listrik tanpa terukurnya di meter, wiring dan lain-lain. Pada dasarnya susut itu sendiri terbagi atas dua yang pertama susut teknis dan susut non teknis pada PT.PLN (Persero) Area Teluk Naga, pada susut non teknis ialah suatu permasalahan yang sangat di waspadai karena dari susut ini PLN mendapat banyak kerugian dari pelanggan seperti mempengaruhi batas daya, mempengaruhi pengukuran energi bisa mencapai 8257,9 kWh/bulan dari 16 pelanggan dan mengalami susut 13809,8 $\mathrm{kWh} /$ bulan oleh karena itu pelanggan yang melakukan penyimpangan tersebut akan dikenakan sanksi berupa denda sebesar Rp.332.830.661 untuk seluruh pelanggan yang melakukan penyimpangan.
\end{abstract}

Kata kunci: Penertiban, Penyusutan, APP, Kerugian 


\section{PENDAHULUAN}

Listrik merupakan sebuah kebutuhan, dapat di katakan sebuah kebutuhan hal tersebut sangat di perlukan di kehidupan. Mulai dari kota-kota besar sampai dengan kota-kota terpencil yang digunakan untuk melakukan aktifitas, dengan adanya listrik segala kegiatan menjadi lebih mudah. Oleh karena itu di butuhkan penertiban Penggunaan Tenaga Listrik untuk keamanan bagi masyarakat akibat bahanya listrik, meningkatkan pelayanan dan menekan susut non teknis yang di sebabkan pemakai tenaga listrik yang tidak sah.

Peran utama pada bidang TE (Transaksi Energi) di PLN Teluk Naga itu sendiri untuk meminimalisir kerugian yang dialami PLN. Oleh karena itu penertiban pemakaian tenaga listrik sangat lah penting dimana menyangkut perencanaan, pemeriksaan, tindakan dan juga penyelesaian terhadap instalasi pemakai tenaga listrik dari PLN. Dimana besarnya susut energi dari PLN berupa prosentase global maka untuk dapat menekan angka susut energi lebih efektif yaitu dengan memisahkan susut antara teknis dengan non teknis. Sehingga dapat diidentifikasi penyebab utama susut distribusi khususnya non teknis, untuk selanjutnya dapat diupayakan solusi untuk menurunkan nilai susut tersebut.

Susut yang terjadi pada jaringan distribusi terbagi atas dua yaitu susut teknis dan susut non teknis, dimana susut teknis disebabkan oleh pengaruh dari umur trafo, luas penampang kabel, arus netral yang terlalu besar, konektor kurang bagus, Panjang jaringan teralalu Panjang. Sedangkan susut non Teknik disebabkan oleh kesalahan pembacaan meter pada pelanggan, penggunaan aliran listrik yang tidak sah, penerangan jalan umum liar.

\section{METODE/PERANCANGAN PENELITIAN}

\subsection{Analisa Kebutuhan}

Dalam penelitian ini kebutuhan yang diperlukan dalam melakukan penelitian ini terdiri dari beberapa hal yaitu data pelanggan yang berada di Bumi Indah dimana data pelanggan tersebut dipilih berdasarkan data pelanggan yang melakukan pencurian, data jumlah daya yang terjual, data jumlah daya yang terpakai, data tegangan yang di suplai, serta data arus yang terpakai, data golongan pelanggaran, lokasi yang diambil yaitu data pelanggan PT. PLN (Persero) Area Teluk Naga.

\subsection{Perancangan Penelitian}

Peran utama pada bidang TE (Transaksi Energi) di PLN Teluk Naga itu sendiri untuk meminimalisir kerugian yang dialami PLN. Oleh karena itu Penertiban Pemaiakain Tenaga Listrik sangat lah penting dimana menyangkut perencanaan, pemeriksaan, tindakan dan juga penyelesaian terhadap instalasi pemakai tenaga listrik dari PLN. 


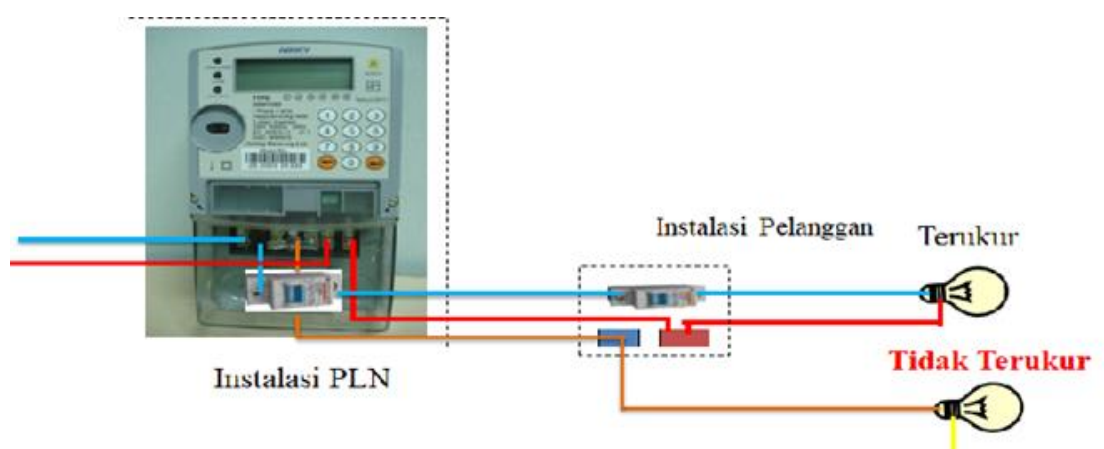

Gambar 1. Kecurangan Pada kWh Meter Pelanggan

Langkah pertama dilakukan melakukan observasi lapangan dengan mencari berbagai pelanggan yang mengalami kecurangan.

Langkah yang kedua secara teknis melakukan perhitungan matematis yang berkaitan dengan apa itu susut.

Secara teknis penelitian ini dapat digambarkan atau diterangkan melalui gambar diagram alir sebagai berikut :

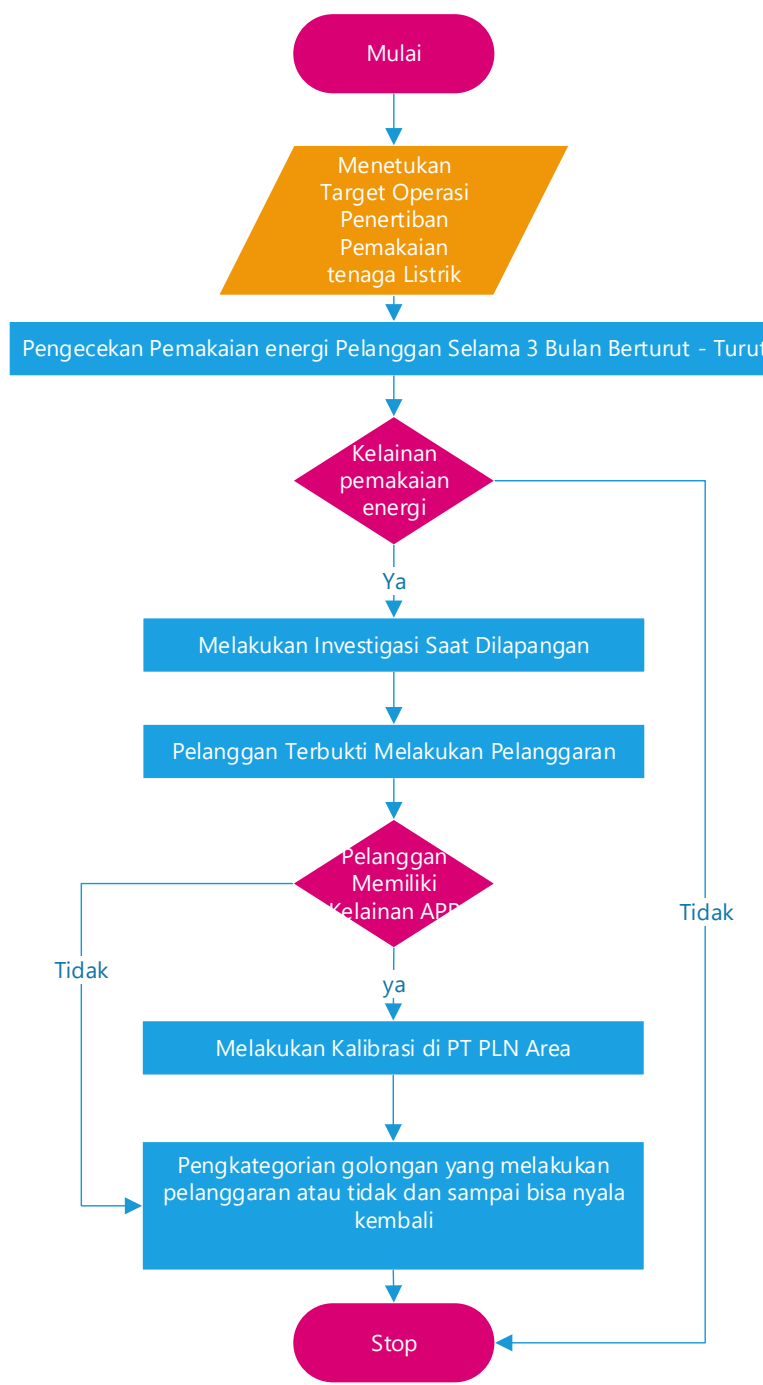

Gambar 2. Diagram Alir 


\subsection{Analisis Perhitungan Susut}

Susut merupakan salah menjadi faktor kerugian yang pasti selalu terjadi dan tidak dapat dihilangkan tapi dapat di minimalisirkan, adapun persamaan yang digunakan ialah:

Susut $=k W h$ Salur -

kWh Jual.

Dimana :

Susut : Total kehilangannya daya yang di hasilkan (watt)

kWh Salur : Jumlah Daya yang di salurkan (watt)

kWh Jual : Jumlah Daya yang terpakai (watt)

Persamaan susut dalam bentuk persentasi dapat dilihat pada persmaan sebagai berikut :

$s=$

Jumlah kWh Salur-Jumlah kWh Jual Jumlah kWh Salur

Putaran piringan merupakan faktor menetukan dimana adanya kecurangan yang dilakukan oleh pelanggan, maka dari itu dapat dilakukan dengan perhitungan sebagai berikut :

$t=$

$\frac{3600 \times 1000}{\operatorname{Ix} V \times C \times \operatorname{Cos} q}$

Dimana :

t $\quad$ : jumlah putaran piringan dalam detik

I : : Arus yang di pakai

$\mathrm{V} \quad$ : Tegangan yang di suplai

C : konstanta meter kWh (putaran/kWh)

Cos $q$ : faktor daya

$3600: 1$ jam menjadi 3600 detik

1000 : 1kW menjadi 1000 watt

Daya listrik merupakan jumlah energi yang diserap atau di hasilkan dalam instalasi rumah. Sumber energi seperti tegangan listrik akan menghasilkan daya listrik sedangkan beban yang terhubung dengannya akan menyerap daya listrik tersebut, dapat digunakan persamaan :

$\mathrm{P}=$

$\left(\frac{\mathrm{V} \times \mathrm{I}}{1000}\right) \times 24$ jam $\times 30$ hari

$\mathrm{P}$ : Daya listrik dengan satuan watt $(\mathrm{W})$

$\mathrm{V}$ : Tegangan listrik dengan satuan Volt $(\mathrm{V})$ 
I : Arus listrik dengan satuan Ampere (A)

Dalam hal ini juga diperlukan perhitungan menentukan jumlah perbandingan daya, dengan rumus sebagai berikut :

$s=$

$\left[\frac{\text { Jumlah } k W h \text { sesungguhnya-Jumlah kWh Pencurian }}{\text { Jumlah } k W h \text { sesungguhnya }}\right] \times 100 \%$

Golongan pelanggaran merupakan penentuan golongan yang dilakukan oleh pelanggan yang didasari dengan jenis pelanggaran itu sendiri mulai dari mempengaruhi daya, batas daya, sambung langsung atau pelanggaran yang bukan pelanggan. Beberapa pelanggaran dibagi menjadi beberapa bagian pelanggaran yaitu pelanggaran golangan satu, pelanggaran golongan dua, dan pelanggaran golongan tiga, pelanggaran golongan 4 .

\section{Pelanggaran Golongan I}

TS1 (Tagihan Susulan 1) $=6 \times\{2$ kali pemakaian seharusnya $X$ Rekening Minimum (Rupiah) Pelanggan Sesuai Tarif Tenaga Listrik\}

\section{Pelanggaran Golongan II}

TS2 $($ Tagihan Susulan 2) $=9 \times 720$ jam $X$ Daya Tersambung $X 0,85 \times$ harga per $k$ Wh yang tertinggi pada golongan tarif pelanggan sesuai Tarif Dasar Listrik

Pelanggaran Golongan III

TS3 $($ Tagihan Susulan 3$)=$ TS1 + TS2

\section{HASIL DAN PEMBAHASAN}

\subsection{Data Penelitian}

Pada penelitian ini peneliti mendapatkan data penelitian berupa gangguan yang terjadi di wilayah PT. PLN (Persero) Area Teluk Naga. Pada penelitian ini dilakukan perhitungan susut (lossis) yang ada pada gardu distribusi GLM 1, data yang didapat yaitu data dari gardu dengan kWh pelanggan. Berikut merupakan Tabel 1. Data Gardu Distribusi.

Tabel 1. Data Gardu Distribusi Area Teluk Naga

\begin{tabular}{|c|l|l|}
\hline No & Data Gardu Distribusi & \multicolumn{1}{|c|}{ Keterangan } \\
\hline 1 & Merk & TRAFOINDO \\
\hline 2 & Tipe & PORTAL \\
\hline 3 & Area & Teluk Naga \\
\hline 4 & Alamat & $\begin{array}{l}\text { Kp. Gelam Pasar } \\
\text { Kemis }\end{array}$ \\
\hline 5 & No Gardu & GLM 1 \\
\hline 6 & Kapasitas & 250 kVA \\
\hline
\end{tabular}

Pelanggan yang melakukan pelanggaran juga dapat dilihat pada tabel dibawah ini, agar mengetahui seberapa besar nilai pencurian yang dilakukan. Berikut data pelanggan yang melakukan pelanggaran. 
Tabel 2. Data Pelanggan Yang Melaukakan Pelanggaran

\begin{tabular}{|c|c|c|c|}
\hline $\begin{array}{c}\text { Kode } \\
\text { Pelanggan }\end{array}$ & Daya & Kategori & Golongan \\
\hline $\mathrm{A}$ & 3500 & Mempengaruhi Daya Energi & P3 \\
\hline B & 2200 & Mempengaruhi Energi & P2 \\
\hline $\mathrm{C}$ & 2200 & Mempengaruhi Energi & P2 \\
\hline $\mathrm{D}$ & 2200 & $\begin{array}{c}\text { Mempengaruhi Daya dan } \\
\text { Energi }\end{array}$ & P3 \\
\hline $\mathrm{E}$ & 2200 & Mempengaruhi Energi & P2 \\
\hline $\mathrm{F}$ & 1300 & Mempengaruhi Energi & $\mathrm{P} 2$ \\
\hline G & 1300 & $\begin{array}{c}\text { Mempengaruhi Daya dan } \\
\text { Energi }\end{array}$ & P3 \\
\hline $\mathrm{H}$ & 1300 & $\begin{array}{c}\text { Mempengaruhi Daya dan } \\
\text { Energi }\end{array}$ & P3 \\
\hline $\mathrm{I}$ & 1300 & Mempengaruhi Energi & P2 \\
\hline $\mathrm{J}$ & 1300 & $\begin{array}{c}\text { Mempengaruhi Daya dan } \\
\text { Energi }\end{array}$ & P3 \\
\hline $\mathrm{K}$ & 1300 & $\begin{array}{c}\text { Mempengaruhi Daya dan } \\
\text { Energi }\end{array}$ & P3 \\
\hline $\mathrm{L}$ & 1300 & Mempengaruhi Energi & P2 \\
\hline$M$ & 1300 & Mempengaruhi Energi & $\mathrm{P} 2$ \\
\hline $\mathrm{N}$ & 1300 & $\begin{array}{c}\text { Mempengaruhi Daya dan } \\
\text { Energi }\end{array}$ & P3 \\
\hline $\mathrm{O}$ & 900 & Mempengaruhi Energi & P2 \\
\hline$P$ & 900 & $\begin{array}{c}\text { Mempengaruhi Daya dan } \\
\text { Energi }\end{array}$ & P3 \\
\hline
\end{tabular}

\subsection{Perhitungan Pengaruh Piringan kWh Akibat Pencurian}

Untuk mengetahui terjadinya kecurangan yang dilakukan oleh pelanggan maka kita melakukan pengecekan langsung pada pelanggan-pelanggan dan beberapa dari keseluruhan pelanggan yang terdapat pada Tabel 2 , berdasarkan hasil perhitungan dengan menggunakan rumus 2 sebagai berikut :

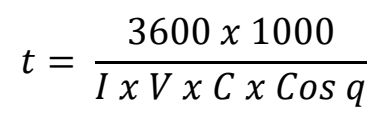

Berikut hasil perhitungan dengan menggunakan rumus diatas dengan diketahui pelanggan yang melakukan pencurian berdasarkan Tabel 2 didapat lama waktu pencurian dapat dilihat pada Tabel 3., sebagai berikut : 
Tabel 3. Data Pengaruh Piringan kWh Akibat Pencurian

\begin{tabular}{|c|c|c|c|}
\hline No & $\begin{array}{c}\text { Kode } \\
\text { Pelanggan }\end{array}$ & $\begin{array}{c}\text { Waktu Putaran } \\
\text { Piringan Dalam } \\
\text { Pencurian } \\
\text { (detik) }\end{array}$ & $\begin{array}{c}\text { Waktu Putaran } \\
\text { Piringan Dalam } \\
\text { Kondisi Sebenarnya } \\
\text { (detik) }\end{array}$ \\
\hline 1 & A & 18,18 & 4,1 \\
\hline 2 & B & 20,45 & 4,09 \\
\hline 3 & C & 20,45 & 4,95 \\
\hline 4 & D & 9 & 2,04 \\
\hline 5 & E & 6,99 & 5,27 \\
\hline 6 & F & 23,3 & 4,67 \\
\hline 7 & G & 54,54 & 4,09 \\
\hline 8 & H & 81,81 & 4,81 \\
\hline 9 & I & 81,81 & 13,6 \\
\hline 10 & J & 40,90 & 3,89 \\
\hline 11 & K & 20 & 4,09 \\
\hline 12 & L & 20,45 & 4,09 \\
\hline 13 & M & 20,45 & 5,84 \\
\hline 14 & N & 18,33 & 2,12 \\
\hline 15 & O & 27,27 & 4,42 \\
\hline 16 & P & 54,54 & 4,30 \\
\hline
\end{tabular}

Pada penelitian ini juga dilakukan perhitungan mengenai daya pemakaian pelanggan, dimana rumus yang digunakan untuk melakukan perhitungan tersebut sebagaimana dapat dilihat pada rumus 4 . Sehingga didapatkan hasil sebagai berikut tertera pada Tabel 4 .

Tabel 4. Hasil Perhitungan Daya Pemakaian Pelanggan

\begin{tabular}{|c|c|c|c|}
\hline No & $\begin{array}{c}\text { Kode } \\
\text { Pelanggan }\end{array}$ & $\begin{array}{c}\text { Daya } \\
\text { Pemakaian } \\
\text { Pelanggan Pada } \\
\text { Saat Pencurian } \\
\text { (kWh/bulan) }\end{array}$ & $\begin{array}{c}\text { Daya Pemakaian } \\
\text { Pelanggan Yang } \\
\text { Sesungguhnya } \\
\text { (kWh/bulan) }\end{array}$ \\
\hline 1 & $\mathrm{~A}$ & 142,56 & 617,76 \\
\hline 2 & $\mathrm{~B}$ & 126,72 & 633,6 \\
\hline 3 & $\mathrm{C}$ & 126,72 & 522,72 \\
\hline 4 & $\mathrm{D}$ & 288 & 288 \\
\hline 5 & $\mathrm{E}$ & 0,514 & 491 \\
\hline 6 & $\mathrm{~F}$ & 110,88 & 554,4 \\
\hline 7 & $\mathrm{G}$ & 47,52 & 633,6 \\
\hline 8 & $\mathrm{H}$ & 31,68 & 538,56 \\
\hline 9 & $\mathrm{I}$ & 31,68 & 190 \\
\hline 10 & $\mathrm{~J}$ & 63,36 & 665,28 \\
\hline 11 & $\mathrm{~K}$ & 79,2 & 633,6 \\
\hline 12 & $\mathrm{~L}$ & 126,72 & 633,6 \\
\hline 13 & $\mathrm{M}$ & 126,72 & 443,52 \\
\hline 14 & $\mathrm{~N}$ & 31,68 & 1219,68 \\
\hline 15 & $\mathrm{O}$ & 95,05 & 586,08 \\
\hline 16 & $\mathrm{P}$ & 47,52 & 601,92 \\
\hline
\end{tabular}


Pada penelitian ini juga dihasilkan perbandingan kWh Real Time dengan kWh Kecurangan, perhitungan berdasarkan rumus 5. Didapat hasilnya pada Tabel 5.

Tabel 5. Perbandingan kWh Real Time dan kWh Kecurangan

\begin{tabular}{|c|c|c|c|c|c|}
\hline No & Kode Pelanggan & kWh Real & kWh pelanggaran & Selisih & Dalam Persen \\
\hline 1 & $\mathrm{~A}$ & $617,76 \mathrm{kWh}$ & $146,56 \mathrm{kWh}$ & $471,2 \mathrm{kWh}$ & $76,27 \%$ \\
\hline 2 & $\mathrm{~B}$ & $633,6 \mathrm{kWh}$ & $126,77 \mathrm{kWh}$ & $506,83 \mathrm{kWh}$ & $80 \%$ \\
\hline 3 & $\mathrm{C}$ & $532,72 \mathrm{kWh}$ & $126,72 \mathrm{kWh}$ & $407 \mathrm{kWh}$ & $76,25 \%$ \\
\hline 4 & $\mathrm{D}$ & $1242,72 \mathrm{kWh}$ & $288 \mathrm{kWh}$ & $954,72 \mathrm{kWh}$ & $76,8 \%$ \\
\hline 5 & $\mathrm{E}$ & $491 \mathrm{kWh}$ & $370,08 \mathrm{kWh}$ & $120,92 \mathrm{kWh}$ & $24,62 \%$ \\
\hline 6 & $\mathrm{~F}$ & $554,4 \mathrm{kWh}$ & $110,88 \mathrm{kWh}$ & $443,52 \mathrm{kWh}$ & $80 \%$ \\
\hline 7 & $\mathrm{G}$ & $633,6 \mathrm{kWh}$ & $47,52 \mathrm{kWh}$ & $586,08 \mathrm{kWh}$ & $92,5 \%$ \\
\hline 8 & $\mathrm{H}$ & $538,56 \mathrm{kWh}$ & $31,68 \mathrm{kWh}$ & $506,88 \mathrm{kWh}$ & $95 \%$ \\
\hline 9 & 1 & $190 \mathrm{kWh}$ & $31,68 \mathrm{kWh}$ & $158,32 \mathrm{kWh}$ & $83,32 \%$ \\
\hline 10 & $\mathrm{~J}$ & $665,28 \mathrm{kWh}$ & $63,36 \mathrm{kWh}$ & $601,92 \mathrm{kWh}$ & $90,4 \%$ \\
\hline 11 & $\mathrm{~K}$ & $633,6 \mathrm{kWh}$ & $79,2 \mathrm{kWh}$ & $554,4 \mathrm{kWh}$ & $87,5 \%$ \\
\hline 12 & $\mathrm{~L}$ & $633,6 \mathrm{kWh}$ & $126,72 \mathrm{kWh}$ & $566,88 \mathrm{kWh}$ & $80 \%$ \\
\hline 13 & M & $433,52 \mathrm{kWh}$ & $126,72 \mathrm{kWh}$ & $306,8 \mathrm{kWh}$ & $70,7 \%$ \\
\hline 14 & $\mathrm{~N}$ & $1291,68 \mathrm{kWh}$ & $31,68 \mathrm{kWh}$ & $1187,32 \mathrm{kWh}$ & $97,34 \%$ \\
\hline 15 & 0 & $586,08 \mathrm{kWh}$ & 95,05 kWh & $491,03 \mathrm{kWh}$ & $83,78 \%$ \\
\hline 16 & $\mathrm{P}$ & $601,92 \mathrm{kWh}$ & $47,52 \mathrm{kWh}$ & $554,4 \mathrm{kWh}$ & $92,1 \%$ \\
\hline \multicolumn{2}{|r|}{ Jumlah } & $10208,04 \mathrm{kWh}$ & $1850,14 \mathrm{kWh}$ & $8257,9 \mathrm{kWh}$ & $81,87 \%$ \\
\hline
\end{tabular}

Pada penelitian ini dilakukan perhitungan susut (losses) dengan menggunakan rumus 1 yaitu didapat hasil sebagai berikut :

\section{Susut=kWh Salur-kWh Jual}

Perhitungan kWh salur yang ada pada gardu distribusi dengan total pelanggan yang melakukan kecurangan :

$$
\begin{aligned}
\text { Susut } & =(67575,81-53766) \mathrm{kWh} \\
& =13809,81 \mathrm{kWh}
\end{aligned}
$$

Perhitungan kWh salur yang ada pada gardu distribusi dengan total pelanggan sesungguhnya :

$$
\begin{aligned}
\text { Susut } & =(67575,81-62124) \mathrm{kWh} \\
& =5451,81 \mathrm{kWh}
\end{aligned}
$$

Perhitungaan biaya total pelanggaran didapatkan hasil pada Tabel 6 dibawah ini berdasarkan rumus 6 dan 7 sebagai berikut: 
Tabel 6. Perhitungan Total Biaya Pelanggaran

\begin{tabular}{|c|c|c|c|c|c|c|}
\hline No & Kode Pelanggar & P1 & P2 & P3 & P4 & Total \\
\hline 1 & $\mathrm{~A}$ & Rp. 2.465 .030 & Rp. 28.286.223 & Rp. 30.751 .257 & $\mathrm{n} / \mathrm{a}$ & Rp. 30.751 .257 \\
\hline 2 & $\mathrm{~B}$ & $\mathrm{n} / \mathrm{a}$ & Rp. 17.779.912 & $\mathrm{n} / \mathrm{a}$ & $\mathrm{n} / \mathrm{a}$ & Rp. 17.779.912 \\
\hline 3 & $\mathrm{C}$ & $\mathrm{n} / \mathrm{a}$ & Rp. 17.779.912 & $\mathrm{n} / \mathrm{a}$ & $\mathrm{n} / \mathrm{a}$ & Rp. 17.779.912 \\
\hline 4 & D & Rp. 1.549 .447 & Rp. 17.779.912 & Rp. 19.329.359 & $\mathrm{n} / \mathrm{a}$ & Rp. 19.329.359 \\
\hline 5 & $E$ & $\mathrm{n} / \mathrm{a}$ & Rp. 17.779.912 & $\mathrm{n} / \mathrm{a}$ & $\mathrm{n} / \mathrm{a}$ & Rp. 17.779.912 \\
\hline 6 & $\mathrm{~F}$ & $\mathrm{n} / \mathrm{a}$ & Rp. 10.506.096 & $\mathrm{n} / \mathrm{a}$ & $\mathrm{n} / \mathrm{a}$ & Rp. 10.506.096 \\
\hline 7 & G & Rp. 915.582 & Rp. 10.506.096 & Rp. 11.421.679 & $\mathrm{n} / \mathrm{a}$ & Rp. 11.421.679 \\
\hline 8 & $\mathrm{H}$ & Rp. 915.582 & Rp. 10.506.096 & Rp. 11.421 .679 & $\mathrm{n} / \mathrm{a}$ & Rp. 11.421 .679 \\
\hline 9 & 1 & $\mathrm{n} / \mathrm{a}$ & Rp. 10.506.096 & $\mathrm{n} / \mathrm{a}$ & $\mathrm{n} / \mathrm{a}$ & Rp. 10.506.096 \\
\hline 10 & $\mathrm{~J}$ & Rp. 915.582 & Rp. 10.506.096 & Rp. 11.421 .679 & $\mathrm{n} / \mathrm{a}$ & Rp. 11.421 .679 \\
\hline 11 & K & Rp. 915.582 & Rp. 10.506.096 & Rp. 11.421.679 & $\mathrm{n} / \mathrm{a}$ & Rp. 11.421 .679 \\
\hline 12 & $\mathrm{~L}$ & $\mathrm{n} / \mathrm{a}$ & Rp. 10.506.096 & $\mathrm{n} / \mathrm{a}$ & $\mathrm{n} / \mathrm{a}$ & Rp. 10.506 .096 \\
\hline 13 & M & $\mathrm{n} / \mathrm{a}$ & Rp. 10.506 .096 & $\mathrm{n} / \mathrm{a}$ & $\mathrm{n} / \mathrm{a}$ & Rp. 10.506 .096 \\
\hline 14 & $\mathrm{~N}$ & Rp. 915.582 & Rp. 10.506 .096 & Rp. 11.421 .679 & $\mathrm{n} / \mathrm{a}$ & Rp. 11.421 .679 \\
\hline 15 & 0 & $\mathrm{n} / \mathrm{a}$ & Rp. 7.273.600 & $\mathrm{n} / \mathrm{a}$ & $\mathrm{n} / \mathrm{a}$ & Rp. 7.273.600 \\
\hline 16 & $P$ & Rp. 633.864 & Rp. 7.273.600 & Rp. 7.907.464 & $\mathrm{n} / \mathrm{a}$ & Rp. 7.907.464 \\
\hline \multicolumn{2}{|r|}{ Jumlah } & Rp. 9.226.251 & Rp. 208.507.935 & Rp. 115.096 .475 & $n / a$ & Rp. 332.830 .661 \\
\hline
\end{tabular}

Dari Tabel 6 diatas dapat dilihat total yang melakukan pelanggaran sebesar Rp. 332.830 .661

\section{KESIMPULAN DAN SARAN}

\subsection{Perhitungan Pengaruh Piringan kWh Akibat Pencurian}

Peneliti dalam melakukan penelitian diatas dapat disimpulkan bahwa, pada pelanggan yang melakukan pelanggaran atau penyimpangan pada piringan $\mathrm{kWh}$ meter, memiliki lama putaran yang lebih lambat dibandingkan dengan kondisi yang sebenarnya. Seperti pada salah satu contoh pada pelanggan $\mathrm{P}$ dimana saat pelanggan melakukan penyimpangan pada putaran piringan menjadi 54,54 detik sedangkan pada penyimpangan kembali dinormalkan menjadi 3,40 detik. Sedangkan pada pelanggan yang mempengaruhi APP nya dapat diketahui bahwa pemakain $\mathrm{kWh} /$ bulan menjadi lebih sedikit saat dilakukann kecuranga. Energi yang hilang akibat rugi - rugi sebesar $8257,9 \mathrm{kWh} / \mathrm{bulan}$, hal tersebut cukup besar sehingga jika tidak diatasi dengan penertiban pemakaian tenaga listrik maka akan terus bertambah. Pada penelitian ini dapat dilihat bahwa susut yang dialami sekitar $13809,8 \mathrm{kWh} /$ bulan tiap bulannya, dalam penelitian ini juga belum tentu dilakukannya penertiban setiap bulan pada tempat yang sama. Pelanggan yang melakukan pelanggaran akan diberikan penalty dengan total biaya penggantian dari semua pelanggan yang melanggar adalah Rp. 332.830.661.

\subsection{Saran}

Dalam melakukan penelitian, peneliti menyarankan agar dilakukannya penertiban pelangan tenaga listrik secara rutin dan berkala, agar segala kecurangan atau 
penyimpangan yang dilakukan oleh pelanggan agar lebih berkurang, hal tersebut dilakukan agar tidak terjadi kerugian, baik dipihak pelanggan maupun dipihak perusahaan dalam hal ini merupakan PT. PLN (Persero) Area Teluk Naga.

\section{UCAPAN TERIMAKASIH}

Penulis mengucapkan terima kasih kepada Instansi/perusahaan/lembaga yang telah memberi dukungan yang membantu pelaksanaan penelitian dan atau penulisan artikel sehingga dapat diselesaikan dengan baik serta dapat bermanfaat bagi pembacanya.

\section{DAFTAR PUSTAKA}

[1] Daira, Fajra, 2017. Prosedur Penertiban Pemakian Tenaga Listrik (P2TL). Padang Wilayah Sumatra Barat.

[2] Hadisasmita, Oka, 2009. Penekanan Losses Dengan Pemeratan Beban Pada Trafo Distribusi.

[3] Kebijakan Direksi. 2005. Penurunan Losses SDM DJBB. Jawa Barat dan Banten

[4] Peraturan Direksi 088z. 2016. Penertiban Pemakaian Tenaga Listrik (P2TL). Jakarta : Kuningan.

[5] Standar PT PLN (Persero). 2012. Alat Pengukur, Pembatas dan Perlengkapannya. Jakarta Selatan.

[6] Yayan Rayani, Verawati, 2011. Upaya Penurunan Susut Energi dan Pengurangan Energi YangTidak Terjual di PT. PLN (Persero). 